\title{
The Influence of Education and Work-Experience on the Leadership Styles
}

\author{
Bhargava R. Kotur ${ }^{1}$, S. Anbazhagan ${ }^{2}$ \\ Department of Lifelong Learning, Bharathidasan University, Khajamalai Campus, Trichy, TN, India.
}

\begin{abstract}
The study investigated the different leadership styles of the workers in the Chittoor Sugar factory located at the Chittoor town of South India. It was also studied how the factors such as work experience and education influence the leadership styles of the workers. The study mainly concentrated on the three interesting leadership styles that are at the top, middle and the bottom of the leadership authority hierarchy, namely the autocratic, democratic and the laissez-faire leadership styles respectively. Upon study it has been understood that the democratic leadership style is more dominant among the workers. The study indicates that education and work experience both have their respective influence on the worker's own leadership styles. The study reveals that with increase in any one of the two variables, relatively lesser authority is exhibited by the workers. Keywords: Leadership styles, Autocratic, Democratic, Laissez-faire, Education, Work-Experience
\end{abstract}

\section{Introduction}

What is the goal of education? It is nothing but adjustment to environment (John Dewey, 1938). It implies that a person upon education, will adjust or at least capable of trying to adjust to the environment, i.e., education brings about a change in the behavior of a person to environment. This concept applies equally well even to a leader. Upon education the leader will try to adjust to his or her followers and this brings about a change in the leadership behavior of the leader (Van Vugt, 2006; Nusbuga, 2009).

Not only education, but even the work-experience of the leader should undoubtedly affect the leadership behavior (Cagle, 1988; Katozai, 2005) for this factor too, either directly or indirectly educates an individual to certain degree. The aim of this study is to investigate the influence of these two factors on the leadership behavior of an employee - specifically on the workers in the Chittoor Sugar factory located at the Chittoor town of South India.

Various studies, including the study of Kearney (2008) on leadership have investigated the influence of the leader's (boss's) - Education and Work-Experience - on the followers' behavior and performance. But, in contrary to that the aim of this study is to investigate the influence of these two factors - Education and Work Experience - on the worker's own leadership styles.

\section{Related Literature}

Some of the related research studies carried out on this topic are brought into light here, in this portion of the paper. Leader - is a person leading a group of people towards a predefined goal, collectively agreed upon (Andrew, 2009). Yukl (2002) has stated leadership as act of influencing subordinates to accomplish organizational goals through authority. Adeyemi and Bolarinwa (2013) have defined leadership as "the art or process of influencing people so that they will strive willingly towards the achievement of objects". According to Yukl (2002), the process of influencing subordinates may be applied by groups or individuals. This aspect reflects the leadership pattern or styles. A leader follows a set of regulations that form his or her unique leadership style that reflects leader's personality and character (George, 2004). Based on different theories of leadership, leadership has been classified in different ways. One classification appears as autocratic, democratic and laissez faire leadership styles (Adeyemi, 2004). Autocratic leadership style is also referred to as authoritarian leadership and this leader always wants to command, orders his followers to comply. $\mathrm{He} / \mathrm{she}$ communicates to employees what is minimally required (Bass, 1990). A leader with democratic leadership style gives priority to participation in policy making process so that each individual of the organization feels himself/herself as an important member of the organization (Adeyemi, 2007). On the other hand, a leader with laissez-faire leadership style may leave the subordinate free to make decision and exercise powers. The leader's role is confined to simply and he/she has least role and participation in the decisions made by group in the organization (Ogunsanwo, 2000). Each of these three styles (autocratic, democratic, and laissez-faire [free-rein]) has their own benefits as well limitations. With passage of time, a leader would switch from one leadership style to the other or might use a combination of these styles. Leaders and styles of leadership may vary based upon age and age groups of the leader and the follows as well. It has been stated, "With an older leader, the team may be more open to a leader's transformational behaviors, because the team members may be more accepting of the leader's special status" (Kearney, 2008). 
Van Vugt (2006) states that: 'In ancestral environments, some situations required the possession of unique and specialized knowledge, for example, where to find a waterhole that has not yet dried up. Knowledge about where to go would have been more likely to be held by older or experienced individuals and, thus leading is expected to correlate positively with experience or knowledge in this domain'. In the present time, evidence for this link between age, experience, knowledge and leadership can still be found in professions that require a considerable amount of specialized knowledge and experience, such as in science, politics, and arts (Van Vugt, 2006).

The study (Mujtaba and Kaifi, 2008), shows that Afghan leaders have higher scores on the relationship orientation which relates to better performance. This indicates that the leaders with some specialized knowledge or skills in psychology can perform better as leaders. On his study on the school principals, Nusbuga (2009) claims that education and experience brings about a change in the leadership attitudes. Cagle (1988) has regarded experience and education as factor that determine the leadership style. Katozai (2005) argued that knowledge is a chief weapon that makes a leader effective and therefore a leader should be educated, experienced and qualified. Nsubuga (2009) has recommended that a continuous professional development (CPD) system for principals be established and institutionalized so that their leadership will become effective. Nsubuga (2009) concluded that unless principals are well equipped with knowledge and skills in management and leadership, they would not be effective leaders.

Apart from the professional and academic knowledge, it is commonly believed that experience might play important roles in leadership behaviors. In many cultures, the myth is that as people get wiser due to more exposure and experience. For example in African culture, experience is considered as a priority for leadership positions in different organizations (Ahiazu, 1989). Same myths are prevalent in Pakistani culture. Gronn (1986) believed that leadership style is rooted in the condition of workplace and less dependent upon whole-of-life learning, personality attributes or in other words on experience. Trompenaars (1993) viewed that leadership styles differ from culture to culture and country to country depending upon life patterns, beliefs and value system or otherwise on the knowledge and experience of the people. Belal A. Kaifi, Bahaudin G. Mujtaba (2010) on their study on Afghans and Americans have concluded that - Culture, Age and Gender - indeed have their impact on the leadership styles of individuals.

Hence, it was considered very important to investigate the influence of experience and educational qualification on the leadership styles of the workers and therefore the study was conducted.

\section{Problem And Objectives}

There has been no known research on the correlation between the employee's leadership styles and the two variables - Education and Work Experience, especially concerning the autocratic, democratic and laissezfaire leadership styles in the Chittoor sugar factory located at the Chittoor town of south India. This study therefore aims to investigate and explore that relationship. Consequently, the research problem is defined as this.

To study the Influence of education and work experience on the leadership styles of the workers in the Chittoor Sugar factory, located at the Chittoor town of Andhra Pradesh, South India.

The objective of this research could be narrowed down to the duo on the sample of the study: A) To Study the different Leadership Styles of workers B) To study the Influence of the variables; education and work experience, on the Leadership Style of the Workers.

\section{Leadership Styles Chosen For The Study}

The basic styles of leadership having been discussed above, for the purpose of this study, only the last three leadership styles are taken into account. The leadership styles chosen for this research study are: a) Autocratic (authoritative) leadership style b) Democratic leadership style and c) Laissez-fair leadership style.

\section{1 Reasons for choosing the above styles}

The reason behind choosing the above said leadership styles for this study are: i) The chosen leadership styles - the autocratic, democratic and laissez-faire fall at the top, the middle and the bottom in terms of exerting authority in the spectrum of the leadership styles (Bass, 1990). The autocratic leadership style is the one that has the maximum control on the group members, exerting peak levels of authority. The sub-ordinates have nothing to share with their leader and their opinions are not cared for. Just they are followers. The laissez-fair leadership has the minimal or no authority on its group members, giving full freedom to the group. The democratic leadership comes in between these two exerting a balanced authority on its group members. It gives freedom to the group members as well controls them too. Naturally, it is interesting to study these three leadership styles and this is one of the reasons for choosing these in this research study. ii) Another reason for selecting these three styles for this study is this: according to sociology, the group psychology has an impact on all the group members too (Kelman, 1958). The group members will acquire certain characteristics of the group without being aware of them. India is a democratic country and naturally we can expect from the above sociology theory 
that the individuals in India will acquire the democratic characteristics more or less. Hence, it is postulated that the democratic traits should be exhibited by many people than any other leadership trait. So, the democratic leadership style is included in this study. iii) The other styles, notably transformational and transactional - have been extensively studied by various researchers in different studies throughout the world. Hence, the other leadership styles were not considered for this study. iv) The questionnaire to test all the leadership styles is costly and is not within the affordable reach of the researcher. This too is one amongst the reasons for the researcher to confine the study only to the selected three leadership styles.

\section{Research Methodology}

This is mainly survey research. This proposed research involves empirical testing of hypotheses set forth for the study. The hypotheses are given under a different section later.

\subsection{Research Universe and Sample}

This research is focused on the Sugar factory at Chittoor town in the state of Andhra Pradesh, south India and the mother tongue of the local people is Telugu, a South Indian language. The population or universe represents the entire group of units which is the focus of the study and the firm under study employs 652 employees of whom around 36 employees hold a supervisory role.

The simple random sampling technique was used in this research study to collect the data. Here, every unit in the universe has the equal chance of being chosen for the study. The researcher posed no defining criteria in selecting the elements from the sample. The sample size of the research comprised 127 of the 652 workers. The sample of 127 workers at the firm, were randomly selected (chosen) by the researcher at the firm. The researcher placed no requirements on the workers while taking the samples.

\subsection{Data Collection}

Only one data gathering technique was employed in this research study and it is the survey method and the questionnaire was used to elicit necessary information. Sekaran (2000) suggests that questionnaires are an efficient data collection mechanism provided the researcher knows exactly what is required and how to measure the variables of interest. Hence, in this study questionnaire is used to collect the data. This method of data collection helps to overcome the issues of cost and time as well. In an attempt to make it beneficial for both the researcher and the firm, and so as not to disrupt operations at the firm, the researcher visited the firm frequently and collected the data from the respondents by giving the questionnaires during the lunch breaks.

\subsection{The Leadership Questionnaire}

The Leadership Questionnaire of the Sage Publications was used to determine the leadership style and potential of the employees. The questionnaire contains 18 statements that identify and measure the key aspects of leadership behavior and each statement in the questionnaire relates to either autocratic or democratic or laissez-faire leadership factors. The respondent is required to judge how frequently the behavior described in the statement is exhibited by him/her.

The Questionnaire uses a scale of 1 to 5, with the five numbers representing the following meanings of the behavior described in the statements. The choice of ' 1 ' indicates - Strongly Disagree, The choice of '2' indicates - Disagree, The choice of '3' indicates - Neural, The choice of '4' indicates - Agree and The choice of ' 5 ' indicates - Strongly agree.

The leadership questionnaire had to be completed by the worker. In the questionnaire, the worker has to answer the questions that describe his/her own leadership style. While the respondents answer the questionnaire, if they find any difficulty or ambiguity the researcher attended them to solve their problem and got the needed data. Each rater was allowed a period of half an hour for the completion and return of the questionnaires.

Another important point is that, majority of the workers are not good at English. So, the questionnaire involved in this study was translated in to the mother tongue of the workers, the Telugu language so that to make their task easier. In this way the need data was collected from the firms by the researcher personally present with the respondents and this data collection took a period of over a month.

\subsection{Reliability and Validity of the Questionnaire}

When evaluating or formulating a specific instrument, reliability and validity are two of the most important aspects to be considered. Reliability and validity are the criteria used to assess whether the research provides a good measure. The Leadership Questionnaire has been tested for reliability and validity in a number of settings, as stated in the official website of the sage publications. The reliability of the instrument has also been proven on many occasions through test-retest, internal consistency methods and alternative methods. 
The Sage Publication's leadership questionnaire is also a standardized tool. It is valid and reliable and has been used extensively worldwide. It has proven to be a strong predictor of leadership styles across a broad range of employees. Hence it has been concluded that the chosen questionnaire was reliable and valid for use in the present research.

\subsection{Data Capturing}

Once all the questionnaires were collected, the researcher coded the gathered data as needed for the study. These scores were then captured by the researcher into a Microsoft Excel spreadsheet for SPSS analysis. These scores were then imported into SPSS for analysis.

\subsection{SPSS Analysis}

The data was presented in a manner that allowed for easy analysis and testing using the Statistical Product and Service Solutions (SPSS). Once the data was imported into a SPSS spreadsheet, from the Microsoft Excel spread sheet, the researcher proceeded to calculate the necessary leadership scores as per the respective scoring keys provided along with the questionnaires, by the respective organizations.

The cross tabulations and Analysis Of Variance (ANOVA) test results were derived from the SPSS tool. Once this is done, statistical tests were done depending on the needs of the hypotheses and these different tests are included in the section under analyses.

\subsection{Rate of Response}

Out of the 127 leaders (workers) surveyed in the sample, 112 completed the questionnaires and have been included in the analysis amounting to a response rate of approximately $88 \%$.

\section{Ethical Considerations}

All the ethical rules of the research participants, has been met in this research study. Bless and Higson Smith (2000) state that, the main rules of data collection are: a) voluntary participation b) the right to privacy c) Freedom and d) Anonymity e) Confidentiality. Even if the employees are willing, the organization might not permit for data collection for various reasons. The organization concerned, though willing to permit the researcher, it might not permit in practice, fearing that the researcher might waste the valuable time of their employees, during the working hours of the organization. After all, it is not the obligation of organizations to allow the researchers to experiment on their employees! But, luckily in the present study, the concerned firm was very favorable to the researcher allowing him to collect the data from the worker. The managers of the firm permitted to collect the data strictly for the research purposes only upon the condition that the names of the workers should not be revealed though the data might be published anonymously and this was all in accordance with the organizational policies and rules.

Another ethical point in research is that of confidentiality. This is concerned with using the collected data for the promised use only and not for some other purposes. Unlike in the case of anonymity, in confidentiality the researcher could identify the respondent based on her response, but should not reveal the data in public. The respondents must be assured that the data collected from them must be used for the intended purpose only and not for something else, that could damage them in some or the other way. The data collected for this research didn't involve any confidential information to great degree, so luckily the researcher managed to collect the data from the workers of the firm with no difficulty.

In order not to take away the valuable time of the workers and not to disrupt the work in the firm, the researcher visited the workers during the time of their lunch breaks and collected the data. The researcher believes that, during this research work no one was affected against the ethics of research and privacy.

\section{Tests and Interpretations}

This study includes three questions in total. Based on relevant tests and tables we are to find the validity of these statements.

\section{Question One}

Q1 - There is significant variance in the number of employees with their inherent leadership styles.

The table presented below reveals that among the sample studied the employees with democratic leadership traits are more (70) compared to the other two. The Laissez-faire leadership traits occupy the second place with count of 30 employees and the autocratic leadership style occupies the end position with 12 employees. 
Number of employees -vs- Leadership Styles Cross tabulation

\begin{tabular}{|c|c|c|c|c|}
\hline & \multicolumn{3}{|c|}{ Leadership styles } & \multirow{2}{*}{ Total No., } \\
\cline { 2 - 4 } & Autocratic & democratic & $\begin{array}{c}\text { Laissez- } \\
\text { faire }\end{array}$ & of employees \\
\hline $\begin{array}{r}\text { Number of } \\
\text { employees }\end{array}$ & 12 & 70 & 30 & 112 \\
\hline
\end{tabular}

From this we can conclude that there is significant variance in the leadership styles exhibited by different employees in the firm, with most of them favoring the democratic leadership style. Hence, the statement - 'there is significant variance in the number of employees with their inherent leadership styles' is proved to be valid. Thus the study proves that the democratic leadership is exhibited by the majority of the employees, compared to the other two styles.

\section{Question Two}

Q2 - There is significant variance among respondent's educational qualifications in terms of leadership styles.

Education - vs - Leadership styles Cross tabulation

\begin{tabular}{|c|c|c|c|c|}
\hline \multirow{2}{*}{ Education } & \multicolumn{3}{|c|}{ Leadership styles } & \multirow{2}{*}{} \\
\cline { 2 - 4 } & Autocratic & Democratic & $\begin{array}{c}\text { Laissez- } \\
\text { faire }\end{array}$ & Total \\
\hline Illiterate & 0 & 2 & 0 & 2 \\
\hline Primary & 0 & 1 & 1 & 2 \\
\hline Secondary & 4 & 11 & 5 & 20 \\
\hline $\begin{array}{c}\text { Higher } \\
\text { Secondary }\end{array}$ & 3 & 11 & 9 & 23 \\
\hline $\begin{array}{c}\text { Degree - or - } \\
\text { Diploma }\end{array}$ & 5 & 35 & 13 & 53 \\
\hline PG and above & 0 & 10 & 2 & 12 \\
\hline Total & 12 & 70 & 30 & 112 \\
\hline
\end{tabular}

The above cross tabulation states that with increasing education, the employees develop more of the democratic leadership characteristics.

ANOVA Test $\sim$ Leadership styles

\begin{tabular}{|c|c|c|c|c|c|}
\hline & Sum of Squares & Df $=\mathrm{n}-1$ & Mean Square & F & Sig. \\
\hline Between Groups & 319.277 & 5 & 63.855 & & \\
\cline { 1 - 4 } Within Groups & 4105.437 & 106 & 38.731 & \multirow{2}{*}{1.649} & NS \\
\cline { 1 - 4 } Total & 4424.714 & 111 & & & \\
\hline
\end{tabular}


From the above table it has been found that the value of ' $F$ ' is not significant at any level. Hence, the statement - "there is significant variance among educational qualifications of employee's in terms of leadership styles" is valid.

The above tables reveal that there is significant variance among the respondents' educational qualifications in terms of leadership styles. The study proves that the leadership styles exhibited by the well educated (with at least a degree) and those who are educated less are different.

\section{Question Three}

Q3 - There is significant variance among respondents experience in terms of Leadership styles

\section{Experience levels -vs- Leadership styles Cross tabulation}

\begin{tabular}{|c|c|c|c|c|}
\hline \multirow{2}{*}{$\begin{array}{l}\text { exp - } \\
\text { level } \\
\text { in } \\
\text { yrs. }\end{array}$} & \multicolumn{3}{|c|}{ Leadership styles } & \multirow[b]{2}{*}{ Total } \\
\hline & Autocratic & Democratic & $\begin{array}{c}\text { Laissez- } \\
\text { faire }\end{array}$ & \\
\hline 5 & 2 & 13 & 1 & 16 \\
\hline 10 & 4 & 10 & 1 & 15 \\
\hline 15 & 1 & 7 & 2 & 10 \\
\hline 20 & 2 & 18 & 10 & 30 \\
\hline 25 & 3 & 22 & 16 & 41 \\
\hline Total & 12 & 70 & 30 & 112 \\
\hline
\end{tabular}

The above cross tabulation states that the employees with lesser experience exhibit different leadership behaviors then those who are relatively higher experienced and with increasing work experience the employees lessen their autocratic leadership characteristics.

ANOVA Leadership styles

\begin{tabular}{|c|c|c|c|c|c|}
\hline & Sum of Squares & Df=n - 1 & Mean Square & F & Sig. \\
\cline { 1 - 4 } Between Groups & 185.733 & 4 & 46.433 & \multirow{2}{*}{1.172} & NS \\
\cline { 1 - 4 } Within Groups & 4238.981 & 107 & 39.617 & & \\
\hline Total & 4424.714 & 111 & & & \\
\hline
\end{tabular}

The one way ANOVA analysis given in the table above reveals that $\mathrm{F}$ value is not significant at any level. Hence, the results prove that the leadership behavior exhibited by the employees depend on their experience levels. Therefore the above tables prove that the statement - "there is significant variance among the employees experience in terms leadership styles" - is valid.

\section{Findings Of The Study}

The findings of this research study, based on the cross tabulations and statistical tests are presented here. a) This study has concluded that all the leadership styles are not equally present in the employees, inherently. The democratic leadership style is more dominant among the employees, the Laissez-faire comes next and the autocratic style of leadership is exhibited by the least number of employees. b) The study states that the more educated employees and the lesser educated employees differ in terms of exhibiting their leadership styles. With increasing educational qualifications the employees exhibit more of the democratic leadership tendencies and those who are educated less are inclined towards the autocratic leadership style. c) The study states that with increasing work experience, the employees exhibit different leadership styles. The lesser 
experienced exhibit the autocratic style more then move toward the democratic and then they finally move towards the laissez-fair leadership trait.

\section{Discussion}

This section is going to discuss, how the findings of this research work are relating to the other findings already established in different studies. It is good news that that are no contradicting findings out of this study and all the finding are in congruent with the established facts of leadership.

a) This study has concluded that all the inherent leadership styles are not equally present in the employees, investigated. The democratic leadership style is more dominant among the employees, the autocratic style comes next and the Laissez-faire leadership is exhibited by least number of employees.

The modern psychology says that, certain traits or customs followed in the group or by the leaders of the group will be easily acquired by the group members (Kelman, 1958). The above finding is in conformity with this sociological principal and as India a democratic country, the citizens of India will naturally get the democratic traits. Hence, it is no wonder that the employees studied in this research too, are inclined more towards the democratic style of leadership.

Another point is that, as this study itself indicates, there is a transition from one leadership style to the other style with growing age, experience, or educational qualifications. The majority of the employees studied in this research do have of these, namely: more age, or more educational qualification or more experience. Hence, it is natural that many of the employees are exhibiting the democratic style of leadership. This finding is in agreement with the findings (2011) of Gholamreza Taleghani, Davood Salmani and Ali Taatian, based on their study on the leadership styles survey in different cultures. The study of Javed Sawati, Saeed Anwar, Iqbal Majoka (2013) conducted on the impact of Qualification, Experience and Age - on the principals' Leadership Styles is also in agreement with the finding of this study.

b) According to this study, the more educated employees and the lesser educated employees differ in terms of exhibiting their leadership styles. With increasing educational qualifications the employees exhibit more of the democratic leadership tendencies and those who are educated less are inclined towards the autocratic leadership style.

This is in conformity with the norms of the educational psychology. In fact, the modern education is based on the fact that people will become more knowledgeable, understanding, broad minded, more adjusting to the environment and less brutal. This principal states that due to the increase in education, the employees will naturally become more capable of understanding their fellow men. Hence, they will use less of their authority on the others and it indicates that they are using less of the autocratic styles and more of the democratic styles. And this finding is in compliance to the already established rules of scientific knowledge, especially with the work of Baron (1996).

c) The work of Ahiazu (1989) and the work of Van Vugt (2006) makes it clear that, with increasing experience in the work place, the employees tend to change better in their leadership style and it is in agreement with this study.

\section{Limitations Of The Study}

Some of the limitations of this research study are: a) only a sample is studied and not all the workers were studied in this research. b) Only the select firm and not all other firms and industries at Chittoor were examined for this study. c) The study is limited is geographically confined to a particular place. d) Only a select few and not all leadership styles were examined in this study e) in any research study the finance is the main constraint, the easily available questionnaires are used for this study. The leadership questionnaire and the performance questionnaire used in this study are the free versions available on-line. The other complex questionnaires are costly to purchase. So, the questionnaires used might have some inherent in-efficiencies. f) Due to the above reasons the findings may not be the general results.

\section{Conclusions}

This is to conclude that the four variables chosen for this study education and work experience - indeed have their respective influence on the leadership styles of the workers. With change in any one of the two factors - education and work experience - will bring out a change in the leadership style of the worker. The study indicates that with increase in education and work experience the workers will tend to exhibit lesser authority.

\section{References}

[1]. Adeyemi, T. O (2004). Educational administration: An Introduction. Lagos: Atlantic Associated Publishers. p.71-86.

[2]. Adeyemi, T.O. (2007): Research Methods and Theses Writing in Educational Studies. Lagos: New Haven Publishers.

[3]. Adeyemi, T.O., Bolarinwa,R. (2013). Principals' Leadership Styles and Student Academic Performance in Secondary Schools in Ekiti State, Nigeria. International Journal of Academic Research in Progressive Education and Development, 2(1), $187-198$. 
[4]. Ahiazu, A. I. (1989). The "Theory A" system of work organization for the modern African workplace. International Studies of Management and Organization, 19(1), 6-27.

[5]. Andrew J. DuBrin (2009): Leadership: New York, USA: Houghton Mifflin Company.

[6]. Baron, R. (1996). The Emotional Quotient Inventory (EQ-i): A Test of Emotional Intelligence. Toronto: Multi-Health Systems.

[7]. Bass, B.M. (1990). Handbook of leadership: Theory, research, \& managerial applications, Third edition. New York: Free Press

[8]. Belal A. Kaifi, Bahaudin G. Mujtaba (2010), "Transformational Leadership of Afghans and Americans: A Study of Culture, Age and Gender", Journal of Service Science \& Management, DOAJ, DOI: doi:10.4236/jssm.2010.31019

[9]. Bless. C and Higson Smith. C (2000): Fundamentals of social research methods, (3Ed.).Lusaka: Juta Education (pvt) ltd.

[10]. Cagle,S.G. (1988). Fiedler's Contingency Theory of Leadership Effectiveness and Appointment of a Committee Chairperson. Dissertation Abstracts International, Volume: 50-07, Section: B, page: 2842

[11]. Davood Salmani, Gholamreza Taleghani, Ali Taatian (2011), "Perception of social justice implication in brain drain management in Iranian educational institutions", Education, Business and Society", Vol. 4, No. 1, pp. $19-32$.

[12]. George, B. (2004). The journey to authenticity. Leader to Leader, 31, 29-35.

[13]. Gronn, P. (1986). The psycho-social dynamics of leading and following. Victoria: Deakin University Press

[14]. Javed Sawati, Saeed Anwar, Iqbal Majoka (2013), "Do Qualification, Experience and Age Matter for Principals Leadership Styles?", International Journal of Academic Research in Business and Social Sciences, DOAJ, DOI: 10.6007/IJARBSS/v3-i7/63

[15]. John Dewey (1938), Experience and education. New York: Simon and Schuster.

[16]. Katozai, M. A. (2005). A Comprehensive Study of Education for Prospective Headmasters and Headmistresses, University publisher, Doger unique book Peshawar

[17]. Kearney. E (2008), "Age differences between leader and followers as a moderator of the relationship between transformational leadership and team performance,” Journal of Occupational \& Organizational Psychology, Vol. 81, No. 4, pp. 803-811.

[18]. Kelman, H. (1958). Compliance, identification, and internalization: Three processes of attitude change. Journal of Conflict Resolution, vol.1, 51-60.

[19]. Mujtaba. B. G. and Kaifi. B. A. (2008), "Afghan and American professionals' leadership orientation toward tasks and relationships: Are there tendencies toward convergence or divergence?" Fortune Journal of International Management, Vol. 5, No. 1 , pp. 107-125.

[20]. Nsubuga, Y. K. (2009). Analysis of Leadership Styles and School Performance of Secondary Schools in Uganda. Doctoral thesis. Port Elizabeth: Department of Education, Nelson Mandela Metropolitan University. Uganda.

[21]. Ogunsanwo, O. A. (2000). Modern Principles and Techniques of Management Ibadan: External Studies Program, Department of Educational Management University of Ibadan.

[22]. www.sagepub.com/northouseintro2e

[23]. Sekaran. U (2000), Research Methods for Business, 3 ed., New York: Hermitage Publishing Services.

[24]. Trompenaars, F. (1993). Riding the waves of culture: Understanding diversity in global business. Chicago, IL: Irwin.

[25]. Van Vugt. M (2006), "Evolutionary origins of leadership and followership," Personality\& Social Psychology Review, Vol. 10, No. 4, pp. 354-371.

[26]. Yukl. G. (2002). Leadership in Organizations 5th Ed. New Jersey: Prentice Hall 